\title{
BBEP
}

\section{Arranjos institucionais entre o poder público municipal e instituições privadas para oferta de vagas na educação infantil}

Jaqueline dos Santos Oliveira

Raquel Fontes Borghi

\section{Resumo}

Apresenta um mapeamento das parcerias/convênios entre o poder público municipal e a esfera privada para a oferta de vagas na educação infantil nos municípios paulistas grandes. O estudo permitiu identificar diferentes arranjos institucionais entre o poder público municipal e as instituições privadas, em que 30, dos 54 municípios paulistas grandes, recorrem ao atendimento conveniado como forma de atender a demanda local, inclusive com instituições de finalidade lucrativa, diferenciando-se das tradicionais formas de convênios instituídas na educação infantil. O texto baseia-se na análise de literatura sobre a temática e os dados coletados durante a pesquisa, a partir de contatos telefônicos direto com os gestores municipais, sites oficiais dos municípios e sites governamentais.

Palavras-chave: educação infantil; parcerias público-privadas; oferta de vagas; convênios. 


\section{Abstract \\ Institutional arrangements between the municipal public service and private institutions to the offer of vacancies in Early Education}

This paper features a research of the partnerships/agreements between the municipal public services and the private sphere to the offer of vacancies in Early Education, in the large counties of São Paulo. The study allowed us to identify different arrangements between the municipal public service and private institutions, which 30 of the 54 large counties of São Paulo turn to the services from partnerships as a mean to attend the local demand, including the institutions with lucrative purposes, being different of the traditional forms of partnerships instituted in Early Education. The text is based on the literature analysis about the theme and the information collected during the research from phone calls to municipal administrators, municipal official sites and government sites.

Keywords: Early Education; public-private partnerships; offer of vacancies; agreements.

\section{Introdução}

O oferecimento de vagas na educação infantil por instituições privadas conveniadas com o poder público possui no Brasil raízes históricas, principalmente na modalidade creche, uma vez que o atendimento nessas instituições tem seu início a partir não só de iniciativas do poder público, mas também das próprias comunidades, principalmente em instituições comunitárias, filantrópicas e assistenciais, sendo esta uma das origens das creches conveniadas. Entretanto, mudanças expressivas têm sido encontradas nesse cenário, como a política de convênio com instituições privadas com fins lucrativos, que supera as formas tradicionais de parcerias com instituições filantrópicas ou comunitárias. Passa-se, portanto, à inserção das escolas privadas com fins lucrativos, no conjunto de instituições subsidiadas pelo poder público.

Segundo Adrião, Garcia, Borghi e Arelaro (2009), apesar dos avanços legais da década de 1990 no que diz respeito à educação infantil, a prática tradicional de convênios/parcerias entre o poder público e as creches conveniadas foi mantida e até mesmo aprofundada. O processo de descentralização da educação pública paulista - cuja principal medida foi a municipalização do ensino fundamental introduzida no Estado de São Paulo a partir, principalmente, de 1996, via Fundo de Manutenção e Desenvolvimento do Ensino Fundamental e de Valorização do 
Magistério (Fundef), o qual priorizou o ensino fundamental e ampliou as responsabilidades municipais (Adrião; Borghi, 2008) - contribuiu para a tendência de consolidação de convênios/parcerias entre municípios paulistas e iniciativa privada.

Para além dos tradicionais convênios do poder público municipal com instituições sem fins lucrativos para o atendimento em creches, novos arranjos vêm multiplicando-se e firmando-se.

Dessa forma, este trabalho analisa a expansão de parcerias/convênios para oferta de vagas na educação infantil por instituições privadas subvencionadas pelo poder público, pois a pesquisa interinstitucional "Estratégias municipais para a oferta da educação básica: análise de parcerias público-privado no Estado de São Paulo"1 identificou um grande número de municípios com convênios, e, de acordo com o banco de dados "Municípios paulistas e parcerias com setor privado", resultante da pesquisa citada, dos 645 municípios paulistas, 138 declararam ter parceria para oferta de vagas na educação infantil. Destes 138 municípios, selecionamos para estudo os municípios grandes, os quais apresentam de 100.001 a 500 mil habitantes, num total de 30 municípios.

Esclarecemos que o termo "parceria" aqui adotado designa os acordos formalmente firmados pelo poder público com setores da iniciativa privada, entendendo, como Bezerra (2008), que a expressão parceria público-privada: "[...] implica também na capacidade de intervenção que o setor privado passa a dispor junto à administração pública, por meio da assunção total ou parcial de responsabilidades até então atribuídas ao poder público em sua totalidade." (Bezerra, 2008, p. 62-63).

Os casos estudados na pesquisa anteriormente citada evidenciaram diferentes arranjos entre a esfera pública e as instituições privadas tanto stricto sensu, ou seja, com fins lucrativos, quanto do chamado terceiro setor. Como exemplo desses novos arranjos, podemos citar o Programa Bolsa Creche - presente nos municípios de Piracicaba e Hortolândia que consiste em um formato de financiamento adotado para ampliação da oferta de vagas à educação infantil. Esse modelo inova em relação ao tradicional, pois há subvenção de recursos públicos à iniciativa privada com fins lucrativos, que se dá a partir do repasse de verbas considerando um valor per capita para cada aluno atendido gratuitamente pela instituição privada (Domiciano; Adrião, 2005; Domiciano, 2009).

Assim, para efeito da discussão aqui apresentada, interessa-nos o atendimento subvencionado pelo poder público, uma vez que se tem por objetivo discutir os novos arranjos institucionais estabelecidos entre as esferas pública e privada para a oferta da educação infantil. Dessa forma, os resultados aqui apresentados referem-se às principais tendências observadas quanto ao ano em que as creches foram integradas ao
1 Pesquisa financiada pela Fundação de Amparo à Pesquisa do Estado de São Paulo (Fapesp) e coordenada pela Prof ${ }^{a} D^{a}$ Theresa Adrião da Universidade Estadual Paulista "Júlio de Mesquita Filho" (Unesp), Campus de Rio Claro, e composta também pelas professoras doutoras Raquel Borghi (Unesp); Teise Garcia (Universidade de São Paulo/Ribeirão Preto) e Lisete Arelaro (Faculdade de Educação da USP - Feusp), além de alunos de graduação e pós-graduação das três universidades citadas. 
sistema municipal/estadual de ensino, aos tipos de instituições privadas conveniadas e o número destas, ao formato dos subsídios públicos repassados às instituições privadas e às justificativas para a opção pelo convênio, bem como uma breve caracterização dos municípios. Para tanto, a presente investigação exigiu contato telefônico com secretários municipais de educação ou supervisores/coordenadores da educação infantil de cada município, além de pesquisa bibliográfica, consulta a sites oficiais dos municípios e sites governamentais.

\section{Caracterização dos municípios pesquisados}

O Estado de São Paulo é dividido em 645 municípios, dos quais 295 têm até 10 mil habitantes (muito pequenos); 234, de 10.001 a 50 mil (pequenos); 54, de 50.001 a 100 mil (médios); 54, de 100.001 a 500 mil (grandes); 6, de 500.001 a um milhão (muito grandes); e apenas 2 municípios têm mais de um milhão de habitantes (metropolitanos).

Os municípios selecionados para esta pesquisa foram os municípios paulistas grandes, sendo que, dos 54, 55,55\%, ou seja, 30 municípios, ${ }^{2}$ declararam possuir convênio/parceria com a esfera privada para oferta de vagas na educação infantil, e é sobre este conjunto a análise presente neste trabalho.

Na Tabela 1, apresentamos alguns indicadores dos municípios estudados.

De acordo com os dados da Tabela 1, os municípios de Americana, Araçatuba, Araras, Atibaia, Diadema, Franca, Itu, Jundiaí, Piracicaba, Presidente Prudente, Santa Bárbara d' Oeste, São Caetano do Sul e São Carlos alcançaram um Índice de Desenvolvimento Humano (IDH) superior ao do Estado de São Paulo, que no mesmo período correspondia a 0,814, o município de Limeira apresentou índice igual ao do Estado, sendo que os demais municípios analisados se encontram abaixo dessa média.

No que se refere ao Produto Interno Bruto (PIB per capita), São Caetano do Sul se destaca apresentando um PIB per capita de R\$62.458,89 em 2007, o que indica um "alto desenvolvimento" do município. Já o município com o menor indicador é Francisco Morato, com o PIB equivalente a R\$ 4.282,20. O PIB per capita de São Caetano do Sul é 14 vezes superior ao de Francisco Morato. Os dois municípios apresentam número de habitantes próximos e possuem convênios para oferta de educação infantil. Dessa forma, não é possível afirmar que a presença de um baixo PIB explicaria a busca de municípios por convênios com instituições privadas para oferta de vagas na educação infantil.

A seguir as principais tendências observadas no conjunto dos municípios analisados e que indicam novos arranjos entre a esfera pública e a privada. 
Tabela 1 - Indicadores Municipais

\begin{tabular}{|c|c|c|c|}
\hline Municípios & $\begin{array}{l}\text { População } \\
\text { (2000) }\end{array}$ & $\begin{array}{c}\text { IDH } \\
(2000)\end{array}$ & $\begin{array}{c}\text { PIB per capita } \\
(2007)\end{array}$ \\
\hline Americana & 182084 & 0,840 & $26.557,60$ \\
\hline Araçatuba & 169240 & 0,848 & $13.894,64$ \\
\hline Araras & 104205 & 0,828 & $19.318,96$ \\
\hline Atibaia & 111055 & 0,819 & $17.043,65$ \\
\hline Cubatão & 108309 & 0,772 & $51.968,25$ \\
\hline Diadema & 357064 & 0,826 & $6.076,07$ \\
\hline Embu & 207663 & 0,772 & $10.430,56$ \\
\hline Ferraz de Vasconcelos & 142377 & 0,772 & $6.076,07$ \\
\hline Franca & 287737 & 0,820 & $11.205,22$ \\
\hline Francisco Morato & 133738 & 0,738 & $4.282,20$ \\
\hline Franco da Rocha & 108122 & 0,778 & $12.098,70$ \\
\hline Guarujá & 265155 & 0,788 & $9.800,14$ \\
\hline Hortolândia & 151669 & 0,790 & $12.098,70$ \\
\hline Itapecerica da Serra & 129156 & 0,783 & $15.238,06$ \\
\hline Itaquaquecetuba & 272416 & 0,744 & $6.928,39$ \\
\hline Itu & 135304 & 0,815 & $23.516,35$ \\
\hline Jacareí & 191358 & 0,809 & $19.656,85$ \\
\hline Jundiaí & 322798 & 0,857 & $40.703,90$ \\
\hline Limeira & 248632 & 0,814 & $19.108,73$ \\
\hline Mauá & 363112 & 0,781 & $13.394,59$ \\
\hline Mogi das Cruzes & 329680 & 0,801 & $15.250,95$ \\
\hline Piracicaba & 329158 & 0,836 & $21.766,25$ \\
\hline Presidente Prudente & 189104 & 0,846 & $14.651,93$ \\
\hline Santa Bárbara d' Oeste & 169735 & 0,819 & $15.409,38$ \\
\hline São Caetano do Sul & 140144 & 0,919 & $62.458,89$ \\
\hline São Carlos & 192923 & 0,841 & $16.441,30$ \\
\hline São Vicente & 302678 & 0,798 & $6.739,94$ \\
\hline Sumaré & 196055 & 0,800 & $24.790,82$ \\
\hline Suzano & 228439 & 0,775 & $19.797,83$ \\
\hline Taboão da Serra & 197460 & 0,809 & $16.337,93$ \\
\hline
\end{tabular}

Fonte: Banco de dados "Municípios paulistas e parcerias com setor privado" (população e Índice de Desenvolvimento Humano - IDH) e Fundação Sistema Estadual de Análise de Dados - Seade (PIB per capita).

\section{Ano de integração das creches ao sistema municipal/estadual de ensino}

Até o ano de 1996, as creches estavam sob responsabilidade da área da assistência e/ou promoção social e não faziam parte do sistema educacional. A partir da Lei de Diretrizes e Bases da Educação Nacional (LDB) de 1996, a educação infantil foi reconhecida como primeira etapa 
da educação básica e dividida em creches ( 0 a 3 anos) e pré-escolas (4 a 6 anos). Em seu art. 89, estabeleceu que "as creches e pré-escolas existentes ou que venham a ser criadas deverão, no prazo de três anos, a contar da publicação desta Lei, integrar-se ao respectivo sistema de ensino" (Brasil, 1996); o que foi considerado por diversos autores (Nascimento, 1999; Kuhlmann, 1999; Fullgraf, 2008) um ganho para a educação infantil, em termos de garantia dos direitos da criança pequena à educação.

A partir dessa realidade, analisamos nos municípios selecionados quando ocorreu essa integração.

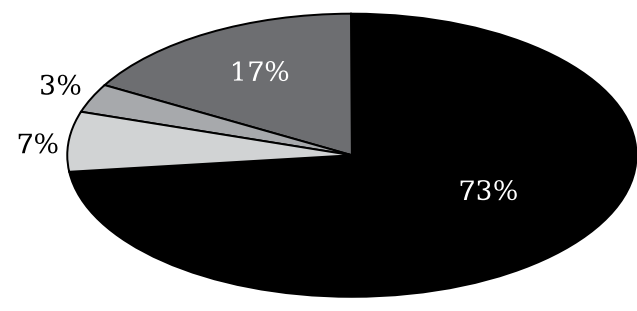

Sistema Municipal

$\square$ Sistema Estadual

$\square$ Assistência Social

Não Informado

Gráfico 1 - Situação das Creches

Pelo Gráfico 1, podemos observar que, nos 30 municípios estudados, 97\% das creches estão integradas ao sistema de ensino, sendo 73\% no municipal e 7\% no estadual. Em 17\% dos municípios, foi nos informado que já houve a integração, porém não nos disseram o ano em que ocorreu. Há, ainda, 3\% dos municípios em que as creches fazem parte da área de assistência social, não sendo integradas ao sistema de ensino.

No Gráfico 2, podemos observar quando ocorreu a integração das creches ao sistema municipal/estadual de ensino.

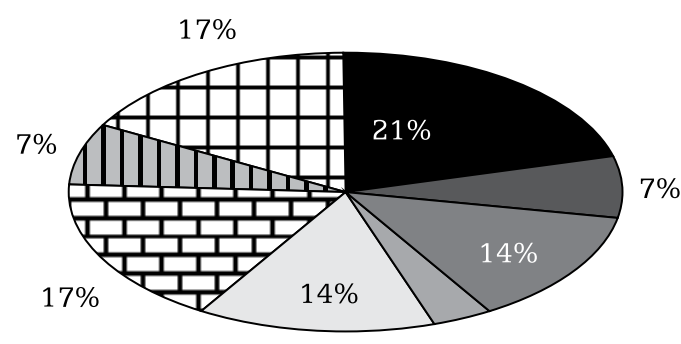

$3 \%$

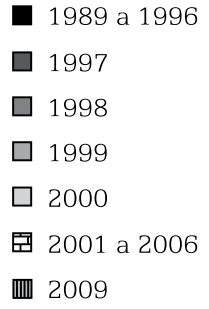

囲 Não informado

Gráfico 2 - Ano de Integração das Creches ao Sistema de Ensino

Pelos dados, observamos que $21 \%$ dos municípios tiveram as creches integradas ao sistema de ensino em período anterior a LDB de 1996. No 
ano de 1997, tivemos 7\% de integração; em 1998, 14\%; em 1999, 3\%; no ano de 2000, um ano após o término do prazo estabelecido pela LDB, 14\% dos municípios tiveram as creches integradas ao sistema de ensino; de 2001 a 2006, 17\%; e, em 2009, 7\%. Os municípios que informaram que as creches já foram integradas ao sistema de ensino, mas não souberam precisar o ano, correspondem a 17\%. Os dados mostram que a integração das creches aos sistemas de ensino ocorreu progressivamente e se estenderam após o período estabelecido pela LDB, o que pode demonstrar a dificuldade dos municípios em cumprir os instrumentos legais em um período tão curto.

\section{Análise do ano de início das parcerias/convênios}

Quanto ao ano de início das parcerias/convênios nesses municípios, nota-se que foi variado, mas grande parte se deu depois de 2000, correspondendo a 56,66\% do total.

No Gráfico 3, podemos observar o ano de início dos convênios por períodos.

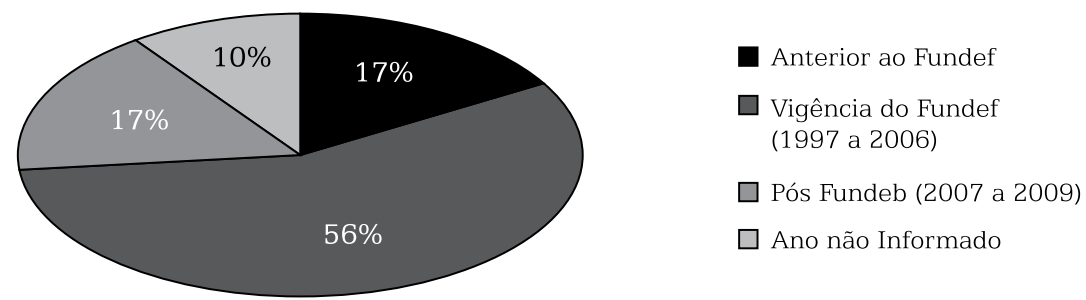

Gráfico 3 - Ano de Início das Parcerias/Convênios

Os dados permitem constatar que 56\% dos convênios se iniciaram no período do Fundef (1997-2006), o qual privilegiava o ensino fundamental e deixava os demais níveis à mercê das iniciativas do poder público municipal em resolver o impasse - atender a outras etapas e modalidades com uma quantidade menor de recursos (Oliveira, 2010).

Ressaltamos, ainda, a existência de casos em que o convênio para a oferta de vagas teve início antes de 1996, uma vez que historicamente as administrações municipais fizeram uso de convênios com instituições sem fins lucrativos para cobrir o precário atendimento às creches. Apontamos também que, pelos dados apresentados, 17\% dos municípios tiveram o convênio iniciado a partir da regulamentação do Fundo de Manutenção e Desenvolvimento da Educação Básica e de Valorização dos Profissionais da Educação (Fundeb) - consideramos que, para nossa análise, são apenas três anos (2007-2009) do novo fundo, sendo cinco convênios para o período um número expressivo. 
Assim, entendemos como Pinto (2007) e Arelaro (2008) que o Fundeb pode e está contribuindo com a consolidação e aprofundamento de convênios entre o setor público e privado, por permitir a inclusão das instituições privadas conveniadas no mecanismo de distribuição dos recursos.

Lembramos que durante o período em estudo, no que refere ao término das parcerias, apenas duas delas foram encerradas no ano de 2009, sendo que as demais continuam em vigor.

\section{Tipo de instituições conveniadas}

As instituições parceiras/conveniadas se dividem em: sem fins lucrativos e com fins lucrativos.

As sem fins lucrativos se dividem em: filantrópicas, comunitárias, confessionais, associações e organizações não governamentais (ONGs). Instituições estas da chamada sociedade civil, ou "terceiro setor", entendido aqui como "[...] o conjunto de 'entidades públicas não-estatais', mas regido pelo direito civil privado" (Adrião; Garcia; Borghi; Arelaro, 2009). Já as instituições com fins lucrativos são as privadas stricto sensu.

No Gráfico 4, apresentamos o percentual de parcerias que ocorrem apenas com instituições sem fins lucrativos, ou exclusivamente com instituições com fins lucrativos ou que apresentam convênios com instituições tanto sem fins lucrativos quanto com fins lucrativos.

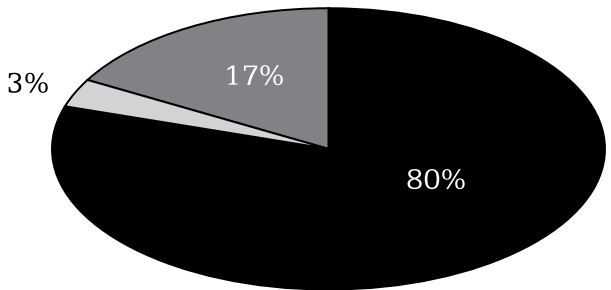

Exclusivamente sem fins lucrativos

$\square$ Exclusivamente com fins lucrativos

$\square$ Com fins lucrativos + sem fins lucrativos

Gráfico 4 - Instituições Parceiras

Pelos dados, observa-se que 3\% dos municípios apresentam convênios apenas com instituições de fins lucrativos, ou seja, um município tem convênio exclusivamente com instituição privada stricto sensu; 5 municípios (17\%) apresentam convênios tanto com entidades sem fins lucrativos quanto com fins lucrativos; e 24 municípios (80\%), com instituições sem fins lucrativos. Pelos dados, é possível observar o avanço das instituições privadas stricto sensu que firmam parceria com o poder público para serem subvencionadas por ele.

As parcerias com instituições privadas stricto sensu são mais atuais, iniciadas a partir de 2001, que é o caso de Piracicaba, 2005 em Hortolândia, 2007 em Sumaré e Limeira e 2009 em Araras. Esses dados 
indicam que novos arranjos vêm se consolidando, distinguindo-se dos tradicionais convênios instituídos na educação infantil, constituindo-se uma nova política de conveniamento.

\section{Formato dos subsídios: tipo e valores}

O Gráfico 5 nos permite observar a tendência do tipo de subsídio nos municípios paulistas de 100.001 a 500 mil habitantes que apresentam parceria para oferta de vagas na educação infantil.

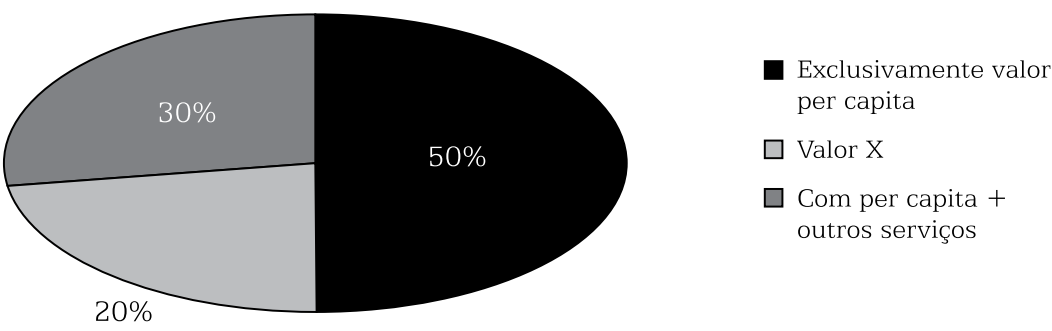

\section{Gráfico 5 - Tipo de Subsídio}

Pelo Gráfico 5, observa-se que 50\% dos municípios repassam às instituições conveniadas um valor per capita. Se somarmos a estes os que também repassam um valor per capita mais algum outro tipo de benefício, temos $80 \%$ dos municípios que adotaram o valor per capita como forma de subvenção às instituições privadas. Em apenas 20\% dos municípios a forma de subvenção não é o per capita, mas um valor geral, fechado, repassado à instituição parceira independentemente do número de alunos matriculados conveniados.

A Tabela 2 permite observar, além do tipo de subsídio, o valor que os municípios repassam às instituições conveniadas.

Os dados apresentados na Tabela 2 mostram que a tendência observada no conjunto dos municípios no que se refere ao formato do subsídio é o valor per capita, do qual o poder público local repassa recursos às instituições escolares em função do número de alunos matriculados.

Os valores per capita repassados às instituições conveniadas variam de um município para outro, mas em torno de $\mathrm{R} \$$ 80,00 e $\mathrm{R} \$ 355,00$, entretanto, a grande maioria se encontra na faixa de $\mathrm{R} \$ 180,00$ e R\$ 200,00. O município de Limeira é o que melhor paga por aluno às instituições conveniadas ( $\mathrm{R} \$ 355,00)$, que é um valor maior do que certas mensalidades de algumas escolas de educação infantil; vale dizer ainda que, nesse município, há convênio com instituições com fins lucrativos. Alguns autores (Arelaro, 2008; Campos, 1988; Pinto, 2007) apontam que o valor per capita repassado às instituições conveniadas se constitui de valor 
Tabela 2 - Tipo de Subsídio e Valor do Per Capita/ Mês (Valores para os Anos de 2009 e 2010)

\begin{tabular}{|c|c|c|}
\hline Municípios & Tipo de subsídio & Valor do per capita \\
\hline Americana & Per capita + verba PNAE & $\begin{array}{l}0 \text { a } 3 \text { anos }=R \$ 164,71 \\
4 \text { a } 5 \text { anos }=R \$ 80,00\end{array}$ \\
\hline Araçatuba & $\begin{array}{l}\text { Per capita }+ \text { pagamento dos } \\
\text { professores }+ \text { merenda }\end{array}$ & * \\
\hline Araras & Per capita & $\mathrm{R} \$ 270,00$ \\
\hline Atibaia & Per capita & $\mathrm{R} \$ 123,00$ \\
\hline Cubatão & Per capita & * \\
\hline Diadema & Per capita & $\mathrm{R} \$ 240,00$ \\
\hline Embu & Per capita + material de limpeza & * \\
\hline Ferraz de Vasconcelos & $\begin{array}{l}\text { Per capita }+ \text { merenda }+ \text { material } \\
\text { pedagógico }\end{array}$ & $\mathrm{R} \$ 160,00$ \\
\hline Franca & $\begin{array}{l}\text { Per capita }+ \text { merenda }+ \text { Atendimento } \\
\text { médico e odontológico }\end{array}$ & $\begin{array}{l}0 \text { a } 1 \text { ano }=R \$ 188,24 \\
2 \text { a } 5 \text { anos }=R \$ 129,84\end{array}$ \\
\hline Francisco Morato & $\begin{array}{l}\mathrm{R} \$ 500,00+\text { pagamento professores } \\
+ \text { merenda }\end{array}$ & ** \\
\hline Franco da Rocha & Verba Ação Social + merenda & ** \\
\hline Guarujá & Per capita + "ajuda de custo" & $\begin{array}{l}\text { Meio período }=* \\
\text { Período integral }=\mathrm{R} \$ 262,00\end{array}$ \\
\hline Hortolândia & Per capita & * \\
\hline Itapecerica & Per capita + merenda & $\mathrm{R} \$ 84,00$ \\
\hline Itaquaquecetuba & Per capita & $\mathrm{R} \$ 106,00$ \\
\hline Itu & Per capita & $\mathrm{R} \$ 180,00$ a $\mathrm{R} \$ 200,00$ \\
\hline Jacareí & $\begin{array}{l}\text { Per capita }+ \text { merenda }+ \text { passe } \\
\text { escolar }+ \text { manutenção do prédio }\end{array}$ & $\begin{array}{l}\text { Meio período }=R \$ 85,00 \\
\text { Período integral }=R \$ 170,00\end{array}$ \\
\hline Jundiaí & Per capita & * \\
\hline Limeira & Per capita & Período integral $=\mathrm{R} \$ 355,00$ \\
\hline Mauá & Per capita & * \\
\hline Mogi das Cruzes & Per capita & * \\
\hline Piracicaba & Per capita & * \\
\hline Presidente Prudente & $\begin{array}{l}\text { Per capita }+ \text { merenda }+ \text { material de } \\
\text { limpeza }\end{array}$ & * \\
\hline $\begin{array}{l}\text { Santa Bárbara d' } \\
\text { Oeste }\end{array}$ & $\begin{array}{l}\text { Valor } \mathrm{x}+\text { merenda }+ \text { pagamento dos } \\
\text { professores }+ \text { material pedagógico }\end{array}$ & $* *$ \\
\hline São Caetano do Sul & $\begin{array}{l}\text { Valor } x+\text { merenda }+ \text { pagamento dos } \\
\text { funcionários }\end{array}$ & $* *$ \\
\hline São Carlos & Per capita & $\begin{array}{l}0 \text { a } 2 \text { anos }=R \$ 100,00 \\
3 \text { a } 6 \text { anos }=R \$ 80,00\end{array}$ \\
\hline São Vicente & $\begin{array}{l}\text { Verba para pagamento de } \\
\text { funcionários }+ \text { merenda }+ \text { água }+ \text { luz }\end{array}$ & $* *$ \\
\hline Sumaré & Per capita & $\begin{array}{l}\text { Meio período }=R \$ 100,00 \\
\text { Período integral }=R \$ 250,00\end{array}$ \\
\hline Suzano & $\begin{array}{l}\text { Per capita }+ \text { merenda }+ \text { material } \\
\text { pedagógico }+ \text { uniforme }+ \text { água }+ \text { luz } \\
+ \text { telefone }\end{array}$ & * \\
\hline Taboão da Serra & Per capita & $*$ \\
\hline
\end{tabular}


bem abaixo do atendimento direto, o que se evidencia em grande parte dos municípios analisados, entretanto, há casos em que essa situação não se verifica, como em Limeira. Pesquisa recente aponta para diferenciações nos custos, em que os gastos por aluno em alguns municípios são inferiores aos da instituição conveniada, e em outros casos é nítida a economia dos municípios com os convênios (Adrião; Garcia; Borghi; Arelaro, 2009).

O documento "Orientações sobre convênios entre secretarias municipais de educação e instituições comunitárias, confessionais ou filantrópicas sem fins lucrativos para a oferta de educação infantil" ratifica o fato de o repasse às instituições conveniadas ser inferior ao definir os fatores de ponderação fixados para 2009 em:

I - creche em tempo integral:

a) pública: 1,10;

b) Conveniada: 0,95. (Brasil. MEC, SEB, 2009 - grifos nossos).

Apontamos ainda que os recursos destinados às instituições conveniadas são provenientes do Fundeb, exceto no município de Limeira, em que o recurso destinado pelo poder público, segundo Agente de Desenvolvimento Educacional contatado, é proveniente dos recursos próprios que o município deve investir em educação, uma vez que o Fundeb não permite a subvenção de instituições privadas com fins lucrativos. Como aponta Domiciano (2009), a subvenção pública aos estabelecimentos privados com fins lucrativos não encontra respaldo legal nas legislações brasileiras.

Segundo o documento do MEC, "o montante de recursos do Fundeb repassado à instituição conveniada é definido pela Secretaria Municipal de Educação [SME] e deve estar previsto no 'termo de convênio firmado entre a instituição e o Poder Executivo competente'" (Brasil. MEC, SEB, 2009 , p. 26). Lembramos que em alguns casos dos municípios aqui estudados o valor per capita é fixado pelo executivo municipal, em outros, pela Câmara dos vereadores, isto é, pelo Poder Legislativo, e, em outros, pela própria SME.

Também conforme o documento do MEC, os recursos do Fundeb repassados às instituições conveniadas deverão ser utilizados em ações consideradas como de Manutenção e Desenvolvimento do Ensino (MDE), as instituições devem aplicar os recursos públicos recebidos exclusivamente no cumprimento do objetivo do convênio, sendo os dirigentes das instituições conveniadas responsáveis pela prestação de contas (Brasil. MEC, SEB, 2009).

Observa-se também que, além do repasse do valor per capita, o poder público em alguns casos ainda é responsável pela merenda escolar, material pedagógico e de limpeza, pagamento de professores e de funcionário, manutenção do prédio, pagamento de água, luz, telefone, entre outros serviços. Segundo esse documento, para celebração do convênio, é definido o: "4. estabelecimento da contrapartida, que é a parcela de participação do convenente na consecução do objeto do 
convênio, que pode ser concretizado mediante o aporte de recursos financeiros ou alocação de bens, materiais e serviços que possam ser economicamente mensuráveis" (Brasil. MEC, SEB, 2009, p. 27).

O município de Guarujá apresenta um caso interessante, pois se tem creches conveniadas e creches subvencionadas, sendo que estas podem cobrar das famílias uma mensalidade razoável - um exemplo dessa prática ocorre no Chile, em que instituições privadas recebem subvenção pública e podem cobrar uma mensalidade razoável dos alunos (Cosse, 2003; David, 2008).

Essa forma de transferência de recursos públicos à esfera privada foi uma das que mais se difundiu nos últimos anos no cenário internacional, a esse respeito Cosse aponta que tem sido apresentado por alguns organismos internacionais, especialistas, partidos e governos o subsídio à demanda, em duas formas principais: o financiamento às escolas, segundo o número de matrícula de cada uma, e o subsídio às famílias (voucher), para que paguem as taxas de educação de seus filhos nas escolas que escolherem. Ainda para Cosse (2003, p. 214), "[...] a proposta do subsídio à demanda por meio do financiamento ao setor privado não é novidade para quase todo o mundo, excluída a América do Norte, já que é uma prática habitual; ainda que certamente combinada com o financiamento à oferta 'tradicional'".

Após apresentar dados e discussões sobre o sistema de subsídio à demanda, do tipo voucher em alguns países da América Latina, Cosse (2003, p. 242) afirma que "[...] parece bastante claro que não há justificativa teórica nem empírica que leve a pensar que o sistema de subsídio à demanda é a solução para os problemas do sistema educacional". Para Oliveira (2010), a alocação de recursos públicos à esfera privada não significa solução para os problemas educacionais, e, ainda, essas estratégias estão atreladas as políticas de redução do aparelho do Estado, "proposta" pelo neoliberalismo, bem como pela Terceira Via. Como aponta Peroni (2009, p. 147), "os dois querem racionalizar recursos e diminuir os gastos do Estado com as políticas sociais e diminuir o papel das instituições públicas [...]", isso decorre desse período particular do capitalismo, em que há um esvaziamento das políticas sociais, em especial das políticas sociais como um direito universal - como é o caso da educação.

\section{Análise das justificativas municipais}

Quanto às justificativas para a opção pelo atendimento conveniado, os gestores apresentaram mais de uma e, em alguns casos, um conjunto delas. No Gráfico 6, apresentamos as que mais apareceram nas respostas dos gestores. 


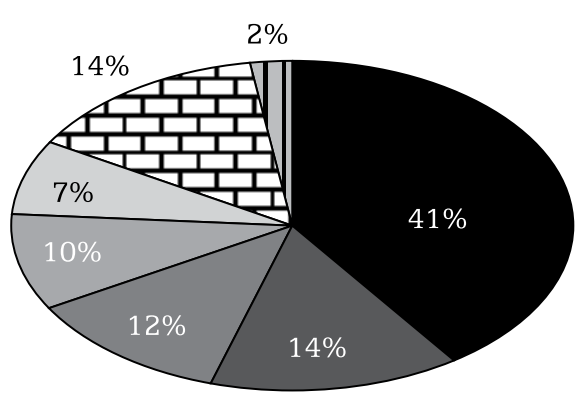

Atender a demanda que é muito grande

$\square$ Falta de espaço/prédio

$\square$ Convênio é mais em conta

$\square$ Já conhecia o serviço prestado/bom atendimento

$\square$ Convênio forma mais rápida de atendimento

田 Outras

四 Política de parceria/convênio

\section{Gráfico 6 - Justificativas para Opção pelo Atendimento Conveniado}

Nas respostas, observamos que os gestores apresentam mais de uma justificativa para opção pelo atendimento conveniado, sendo que as que mais se destacaram foram: atender a demanda/demanda muito grande com 41\%; já conheciam o serviço prestado pelas instituições privadas/bom atendimento com 10\%; convênio como forma mais rápida de atendimento/ medida emergencial com 7\%; falta de espaço para construção e/ou falta de prédio com 14\%; e convênio "é mais em conta" com 12\%. Na categoria "outras", temos as justificativas que apareceram apenas uma vez, entre elas: diálogo interessante; novo modelo de atendimento à criança; Lei de Responsabilidade Fiscal (LRF); suprir e/ou auxiliar as instituições privadas; sociedade desenvolve e o município ajuda para fortalecê-la; e ação do Ministério Público (MP) - esta categoria representa 14\%. Consideramos relevante apresentar no gráfico a reposta: política de conveniamento/ atendimento municipal se dá por parceria, que corresponde a 2\%, por apresentar um ponto importante para a discussão até aqui apresentada, em que os municípios sem recursos suficientes e tendo que dar conta de atender a educação infantil, que é de sua responsabilidade, podem optar em construir uma política de conveniamento em oposição à expansão da rede direta.

Como já apontamos alhures, a expansão da educação infantil nos últimos anos tem levado muitos municípios a optarem pelas parcerias como forma de atender a demanda local, sendo esta uma das justificativas que mais se destacou nos municípios aqui analisados e que foi apontada em pesquisa realizada por Domiciano (2009, p. 87): "[...] atender a demanda reprimida e diminuir a 'lista de espera' na educação infantil, o poder público acreditava que uma provável 'solução', rápida e emblemática, pudesse partir da 'união de forças' entre a prefeitura e a iniciativa privada."

No que diz respeito ao "convênio ser mais em conta", Campos (1988) aponta que é a partir do ponto de vista das políticas públicas, em que o repasse às entidades privadas consideradas sem fins lucrativos é justificado com argumentos ligados a maior eficiência e custos mais baixos do que os dos serviços prestados diretamente pelo Estado. Mas, como apontamos anteriormente, existem diferenciações nos formatos de financiamento das parcerias, bem como nos custos (Adrião; Garcia; Borghi; Arelaro, 2009). 
Quanto à ação do Ministério Público, Mizuki e Silveira (2009) indicam que pode influenciar na expansão do atendimento a esta etapa da educação básica em instituições privadas conveniadas, ainda que nos municípios selecionados para pesquisa apenas um indicou ação do MP como justificativa para o convênio.

Já no que se refere à Lei de Responsabilidade Fiscal, Arelaro (2008, p. 54) aponta que, nas áreas da Saúde, Educação e Assistência, limitar em 60\% dos gastos com pessoal significa, principalmente, o "[...] congelamento dessas atividades pelo Estado", o que pode explicar a busca de municípios por parcerias para não contrariar a Lei e consequentemente não "[...] ser preso e responder por um processo criminal [...]" ou "[...] arcar com pesadas multas financeiras" (p. 53).

Em síntese, podemos dizer que as justificativas para opção de parceria pelos municípios se reportaram em sua grande maioria às dificuldades em prover o atendimento à educação infantil, de modo a atender a demanda ou parte dela. Nesse sentido, o poder público local, em algumas municipalidades, argumentou que o conveniamento seria uma alternativa eficaz e eficiente para resolver o aumento da demanda em um intervalo de tempo reduzido e com menor custo. Além disso, alguns municípios destacaram a importância da participação da sociedade civil para a solução de problemas de caráter social, como a da demanda na educação infantil e na categoria a "sociedade desenvolve e o município ajuda para fortalecê-la".

Como podemos ver, várias são as justificativas para o atendimento conveniado, mas nenhuma expressa preocupação com o tipo de atendimento oferecido e a qualidade dele. A principal preocupação é apenas em atender a demanda e, em alguns casos, não "gastar muito", o que consideramos uma prática questionável, tendo em vista a importância da creche e da pré-escola para o desenvolvimento integral da criança de 0 a 6 anos. Também reconhecemos a insuficiência dos recursos destinados à educação infantil, e assim, como explicita Arelaro (2008), é de se esperar que os municípios busquem alternativas menos dispendiosas para dar conta da grande pressão da demanda por educação infantil, como os convênios. Entretanto, como aponta Domiciano (2009, p. 183), essa medida

[ ] contribui para o avanço da privatização das etapas mais substanciais da educação básica na medida em que viabiliza a transferência de recursos públicos às escolas privadas conveniadas, contribuindo para que o crescimento das matrículas, principalmente nas creches, se generalize na esfera privada, ainda que em muitos municípios estejam "camufladas" como públicas.

A problemática em questão parece uma prática que tende a se generalizar caso não haja mais investimentos em educação. 


\section{Considerações finais}

Este artigo buscou apresentar um mapeamento geral das parcerias/ convênios entre o poder público municipal e a esfera privada para o atendimento da educação infantil nos municípios paulistas grandes. Podemos observar que, desses municípios, 55\% recorrem ao atendimento conveniado como forma de atender a demanda local. Os resultados evidenciaram uma diferenciação entre os tradicionais convênios com instituições privadas sem fins lucrativos e os novos convênios realizados com instituições privadas com fins lucrativos.

Observamos nesses municípios a tendência de uma política consistente de ampliação da oferta de educação infantil a partir da rede privada e com incentivo público por meio do atendimento conveniado. Domiciano (2009) aponta a falta de respaldo legal para a subvenção pública a instituições privadas stricto sensu.

Os dados permitem afirmar que houve uma maior concentração de convênios no período de vigência do Fundef (1997-2006), que privilegiou o ensino fundamental em detrimento das demais etapas da educação básica. Há também a existência de convênios firmados anteriormente, como alguns que iniciaram entre o final da década de 1970 e início da década de 1980. Há uma predominância dos tradicionais convênios com instituições sem fins lucrativos (filantrópicas, comunitárias, associações, confessionais e ONGs), mas há, também, um aumento considerável com instituições stricto sensu, isto é, com fins lucrativos.

A pesquisa aponta a importância de novos estudos sobre essa problemática que esta colocada, tendo em vista que o Fundeb incentiva a política de ampliação de vagas por convênios, o que acaba levando alguns municípios a subvencionar instituições privadas com fins lucrativos.

\section{Referências bibliográficas}

ADRIÃO, T.; GARCIA, T.; BORGHI, R.; ARELARO, L. Estratégias municipais para a oferta da educação básica: análise das parcerias público-privado no Estado de São Paulo. Projeto de pesquisa. 2009.

ADRIÃO, T.; BORGHI, R. Parcerias entre prefeituras e esfera privada: Estratégias privatizantes para a educação pública em São Paulo? In: ADRIÃO, T.; PERONI, V. (Org.). Público e privado na educação: novos elementos para o debate. São Paulo: Xamã, 2008. p. 99-110.

ARELARO, L. A não-transparência nas relações público-privadas: o caso das creches conveniadas. In: ADRIÃO, T.; PERONI, V (Org.). Público e privado na educação: novos elementos para o debate. São Paulo: Xamã, 2008. p. 51-66. 
BEZERRA, E. Parceria público-privada nos municípios de Brotas e Pirassununga: estratégias para a oferta do ensino? 2008. Dissertação (Mestrado em Educação) - Universidade Estadual Paulista, Rio Claro, 2008

BRASIL. Lei n. 9.424, de 24 de dezembro de 1996. Institui o Fundo de Manutenção e Desenvolvimento do Ensino Fundamental e Valorização do Magistério. Diário Oficial da União, Brasília, 25 dez. 1996.

BRASIL. Lei no 11.494, de 20 de junho de 2007. Regulamenta o Fundo de Manutenção e Desenvolvimento da Educação Básica e de Valorização dos Profissionais da Educação (Fundeb), de que trata o art. 60 do Ato das Disposições Constitucionais Transitórias; altera a Lei no 10.195, de 14 de fevereiro de 2001; revoga dispositivos das Leis $\mathrm{n}^{\circ} \mathrm{s} 9.424$, de 24 de dezembro de 1996, 10.880, de 9 de junho de 2004, e 10.845, de 5 de março de 2004; e dá outras providências. Diário Oficial da União, Brasília, 21 jun. 2007. Texto retificado em 22 jun. 2007. Disponível em: < http://www.planalto.gov.br/ccivil_03/_ato2007-2010/2007/Lei/ L11494.htm>. Acesso em: 5 out. 2009.

BRASIL. Lei no 9.394, de 20 de dezembro de 1996. Estabelece as diretrizes e bases da educação nacional. Diário Oficial da União, Brasília, 23 dez. 1996. Disponível em: <http://www.planalto.gov.br/ ccivil_03/leis/L9394.htm>. Acesso em: 5 dez. 2009.

BRASIL. Ministério da Educação (MEC). Secretaria de Educação Básica (SEB). Orientações sobre convênios entre secretarias municipais de educação e instituições comunitárias, confessionais ou filantrópicas sem fins lucrativos para oferta de educação infantil. Brasília, 2009.

CAMPOS, M. M. As organizações não governamentais e a educação préescolar. Cadernos de Pesquisa, São Paulo, n. 67, p. 17-22, nov. 1988.

COSSE, G. Voucher educacional: nova e discutível panacéia para a América Latina. Cadernos de Pesquisa, São Paulo, n. 118, p. 207-246, mar. 2003.

DAVID, D. L. Formatos de financiamento da educação pública obrigatória em vigência no Brasil, Chile e Venezuela. 2008. 54 f. Trabalho de conclusão de curso (Licenciatura em Pedagogia) Universidade Estadual Paulista, Rio Claro, 2008.

DOMICIANO, C. A. O Programa Bolsa Creche nos municípios paulistas de Piracicaba e Hortolândia: uma proposta para alocação de recursos estatais à educação privada? 226 f. Dissertação (Mestrado em Educação) - Instituto de Biociências, Universidade Estadual Paulista, Rio Claro, 2009. 
DOMICIANO, C. A.; ADRIÃO, T. Uma análise do Programa Bolsa Creche no município de Piracicaba. Educação. Teoria e Prática, Rio Claro, v. 13, p. 97-110, 2005.

FULLGRAF, J. B. G. O lugar da educação infantil na sociedade contemporânea. Ciênc. let., Porto Alegre, n. 43, p. 25-40, jan. /jun. 2008.

KUHLMANN JR., M. Educação Infantil e currículo. In: FARIA, A. L. G.; PALHARES, M. S. (Org). Educação Infantil pós-LDB: rumos e defios. Campinas: Autores Associados, 1999. p. 51-65.

MIZUKI, V; SILVEIRA, A. A. D. Parcerias entre os municípios paulistas e a esfera privada para a oferta de vagas na educação infantil: influência da atuação do Ministério Público local? In: SIMPÓSIO BRASILEIRO DE POLÍTICA E ADMINISTRAÇÃO DA EDUCAÇÃO, 24., 2009, Vitória. Trabalhos completos [do] XXIV Simpósio... e III Congresso Interamericano de Política e Administração da Educação. Vitória: Anpae, UFES/PPGE, 2009. Disponível em: < http://www.anpae.org.br/ congressos_antigos/simposio2009/358.pdf $>$.

NASCIMENTO, M. E. P. Os profissionais da educação infantil e a nova Lei de Diretrizes e Bases da Educação Nacional. In: FARIA, A. L. G.; PALHARES, M. S. (Org.). Educação Infantil pós-LDB: rumos e desafios. Campinas: Autores Associados, 1999. p. 99-112.

OLIVEIRA, J. S. Oferta educacional nas creches e parcerias públicoprivado nos municípios paulistas de 100.000 a 500.000 habitantes. Trabalho de conclusão de curso (Licenciatura Plena em Pedagogia) - Instituto de Biociências, Universidade Estadual Paulista, Rio Claro, 2010.

PERONI, Vera Maria Vidal. As parcerias público/privadas na educação e as desigualdades sociais. Caderno de Pesquisa Pensamento Educacional, Curitiba, v. 4, n. 7, p. 139-160, 2009. Disponível em: <http://www.utp.br/Cadernos_de_Pesquisa/pdfs/cad_pesq7/9_as_ parcerias_publico_cp7.pdf>.

PINTO, J. M. A política recente de fundos para o financiamento da educação e seus efeitos no pacto federativo. Educação \& Sociedade, Campinas, v. 28, n. 100, out. 2007.

SÃO PAULO. Fundação Sistema Estadual de Análise de Dados (Seade). Informações dos Municípios Paulistas (IMP). Disponível em:

<http://www.seade.gov.br/produtos/imp/index.php>. 
Arranjos institucionais entre o poder público municipal e instituições privadas

Jaqueline dos Santos Oliveira é mestranda em Educação pela Universidade Estadual Paulista Júlio de Mesquita Filho (Unesp)/Rio Claro. jackylyny06@yahoo.com.br

Raquel Fontes Borghi, doutora em Educação Escolar pela Universidade Estadual Paulista Júlio de Mesquita Filho (Unesp)/Araraquara, é professora assistente da Unesp/Rio Claro.

raborghi@gmail.com

Recebido em 26 de janeiro de 2012.

Aprovado em 7 de novembro de 2012. 